\title{
Structure and Physiology of Developing Neuromuscular Synapses in Culture
}

\author{
T. Takahashi, ${ }^{a}$ Y. Nakajima, K. Hirosawa, ${ }^{b}$ S. Nakajima, and K. Onodera ${ }^{\circ}$ \\ Department of Biological Sciences, Purdue University, West Lafayette, Indiana 47907
}

The structure and function of developing neuromuscular synapes in culture have been investigated. We used neuromuscular junctions formed by coculturing dissociated muscle cells and dissociated neurons obtained from Xenopus embryos. After recording nerve-evoked endplate potentials (e.p.p.s) and spontaneously occurring miniature endplate potentials (m.e.p.p.s) from a given junction, the same specimen was investigated for electron-microscopic histology. We surveyed almost the total area of the junctional region by making serial sections. Even in preparations cocultured for only a short time (4-11 hr), both e.p.p.s and m.e.p.p.s could be obtained. The junctional region of these early synapses revealed a simple structure. The presynaptic terminals contained smooth-surfaced clear vesicles, but there were no presynaptic specializations such as active zones. The width of the synaptic cleft was variable, with predominance of narrow regions (10-30 $\mathrm{nm}$ ), and there was no basal lamina inside the cleft. When the coculture time was $1 \mathrm{~d}$ or longer, the junctional area started to show structural features resembling a mature neuromuscular synapse. In the presynaptic terminal there were active zones, consisting of the presynaptic density and an accumulation of vesicles near the density. In many junctions, the postsynaptic membrane showed densities and thickenings, with a widened synaptic cleft, that contained basal lamina. It is known that growth cones, prior to making neuromuscular junctions, can release the transmitter substance with a very long latency if stimulated repetitively. In contrast, e.p.p.s with short latencies can be evoked by single stimuli soon after the growth cones attach to muscle cells. However, our data did not reveal any structural changes to account for such functional changes. We conclude that the presynaptic specializations, such as active zones, do not seem to be required for eliciting either m.e.p.p.s or e.p.p.s. Active zones should be regarded as structures which may make synaptic

Received Mar. 3, 1986; revised July 7, 1986; accepted July 22, 1986.

We thank Prof Prem S. Puri (Statistics Department, Purdue University) for discussing the probability problem, and Dr. Sandra $\mathbf{R}$. Grabowski for critically reading the manuscript. Thanks are also due to Ms. Pamella Schroeder and Ms. Anita Robinson for their technical and clerical help. This work was supported by NIH Grants AG06093, NS 08601, and a grant from the Muscular Dystrophy Association.

Correspondence should be addressed to Dr. Yasuko Nakajima at the above address.

aresent address: Department of Physiology, Faculty of Medicine, Kyoto University, Kyoto, 606 Japan.

- Present address: Department of Fine Morphology, Institute of Medical Science, University of Tokyo, Tokyo, 108 Japan.

c Present address: Department of Physiology, School of Medicine, Juntendo University, Tokyo, 113 Japan.

Copyright (c) 1987 Society for Neuroscience $0270-6474 / 87 / 020473-09 \$ 02.00 / 0$ transmission more efficient, possibly by localizing both calcium channels and synaptic vesicles to the releasing sites.

Not much is known about the principles governing the formation of synapses during development. In this respect it is desirable to correlate the structural aspects of synaptic formation with the development of physiological functions. The information will help us understand these principles. Several early studies tried to investigate this problem on developing neuromuscular junctions by using in vivo preparations (Kelly, 1966; Hirano, 1967; Teräväinen, 1968; Kelley and Zacks, 1969). In these in vivo studies, however, only limited interpretations were feasible because it is almost impossible to obtain morphological and physiological data on the same synapses.

Early in 1970 several investigators succecded in making ncuromuscular synapses in culture (Crain, 1970; Fischbach, 1970; Kano and Shimada, 1971; Robbins and Yonezawa, 1971). Because of the good visibility in the culture system, it became possible, in theory, to examine more critically the correlation between structure and function. In practice, however, this is a very laborious task. Thus, although several studies have been published on the development of neuromuscular junctions in culture (Koenig and Pecot-Dechavassine, 1971; Pappas et al., 1971; Shimada and Fischman, 1973; Bird and James, 1974; Betz, 1976; Jacob and Lentz, 1979; Peng et al., 1979; Weldon and Cohen, 1979), straightforward interpretations again seem to be difficult because morphological and physiological data were not obtained from the same synapses.

In 1980, Nakajima et al. described the sequences of morphological and physiological development of rat neuromuscular junctions formed in culture. In this work, the same synapses were used to obtain both morphological and physiological data, making the interpretation less ambiguous. One of the limitations of this work, however, was that spontaneously occurring miniature endplate potentials (m.e.p.p.s) were used as the indication of neuromuscular function. It would have been better if both nerve-evoked endplate potentials (e.p.p.s) and m.e.p.p.s were recorded, since these 2 events reflect different aspects of neuromuscular functions.

In the experiments reported here, we attempted to correlate structure and function of developing Xenopus neuromuscular synapses in cell culture. Xenopus neuromuscular junctions are good preparations for such studies since synaptic contacts are established quite quickly during coculture of dissociated nerve and muscle cells (Peng et al., 1979). And at early stages of neuromuscular contact, many muscle cells are singly innervated (not multiply innervated). We first tested the function of a neuromuscular junction by recording both e.p.p.s and m.e.p.p.s, 
Figure 1. A. E.p.p.s and m.e.p.p.s obtained from material cocultured for 6 hr. Arrowheads in $A 1$ and $A 3$ indicate the time of the stimulus. M.e.p.p.s are seen in $A 2$ and $A 3$. Resting potential was $-62 \mathrm{mV} . B$, Effect of $\mathrm{Mn}^{2+}$ on nerve evoked e.p.p.s. The preparation was cocultured for $6 \mathrm{hr}$. First, a control e.p.p. was recorded $(B I)$, and superfusion with a solution in which $\mathrm{Ca}^{2+}$ was replaced by $\mathrm{Mn}^{2+}$ was started. The amplitude of e.p.p. diminished $(B 2)$ and almost disappeared (B3). Record $B 4$ shows a nearly complete recovery of the e.p.p. after normal Ringer's solution was reintroduced. Resting potential at the beginning (B1) was $-64 \mathrm{mV}$, and at the end $(B 4),-60 \mathrm{mV}$.
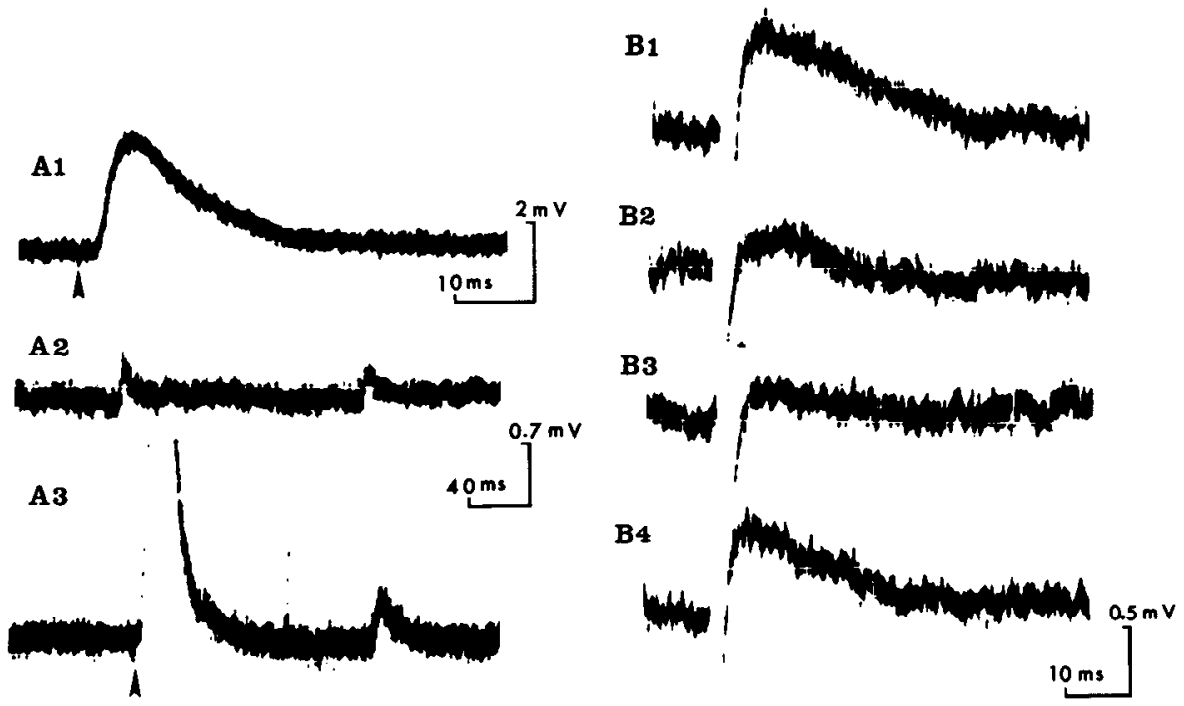

and we then examined the same junction by electron-microscopic histology. In our ultrastructural observations, we have tried to obtain the total picture of the junctional area by making serial sections. Some of the present results presented here have been published previously (Takahashi et al., 1984).

\section{Materials and Methods}

Preparation of cultures. We used embryonic Xenopus neuromuscular synapses in culture. Synapses were formed by coculturing dissociated muscle cells and dissociated neurons. The procedures were similar to those described previously (Peng and Nakajima, 1978; Peng et al., 1980). First, primary muscle cell cultures were prepared from myotomes of stage 19-23 embryos (Nieuwkoop and Faber, 1967). Myotomes were dissected from embryos in Stainberg's solution containing $1 \mathrm{mg} / \mathrm{ml}$ collagenase (Type 1, Sigma, St. Louis, MO) and then dissociated in $\mathrm{CA}^{2+}$ - and $\mathrm{Mg}^{2+}$-free Steinberg's solution containing $0.4 \mathrm{~mm}$ EGTA. Dissociated cells were plated onto $60 \mathrm{~mm}$ tissue culture dishes (Falcon Labware, Oxnard, CA) in a medium containing L-15 (60\%), $1 \%$ fetal calf serum, 100 units penicillin $/ \mathrm{ml}$, and $100 \mu \mathrm{g}$ streptomycin $/ \mathrm{ml}$.

After muscle cells were cultured for 4-7 d, dissociated neurons taken from neural tubes of stage 21-24 embryos werc added to the musclc culture. The dissociation of neural tubes was conducted using a procedure similar to that for myotomes. The culture medium contained
L-15 (60\%), 1-5\% fetal calf serum, penicillin (100 unit $/ \mathrm{ml})$, and streptomycin $(100 \mu \mathrm{g} / \mathrm{ml})$. Amphotericin B (50 $\mu \mathrm{g} / \mathrm{ml}$; Sigma) and gentamicin $(50 \mu \mathrm{g} / \mathrm{ml})$ were sometimes added to the dissecting media to minimize fungal contamination. Neuromuscular contacts started to develop after several hours of coculture.

Electrophysiology. Conventional intracellular microelectrode techniques were used. The culture dish was mounted on the stage of an inverted phase-contrast microscope. The muscle cell was impaled by an intracellular microelectrode filled with $4 \mathrm{M} \mathrm{K}$ acetate or $3 \mathrm{M} \mathrm{KCl}$, with resistance ranging from 30 to $60 \mathrm{M} \Omega$, after beveling the tip.

The neuron was stimulated through an extracellular micropipette filled with Ringer's solution. The tip was fire-polished, and its diameter was $2-10 \mu \mathrm{m}$. The micropipette was placed on the neuronal soma or on a nerve process. The bathing fluid during electrophysiological experiments was a frog Ringer's solution containing $\mathrm{NaCl}, 115 \mathrm{mM} ; \mathrm{KCl}, 2.5 \mathrm{mM}$; $\mathrm{CaCl}_{2}, 10 \mathrm{~mm}$; and HEPES-NaOH buffer, 3-6 mM, pH 7.1-7.4. The experiments were conducted at room temperature (about $24^{\circ} \mathrm{C}$ ).

Electron microscopy. After electrophysiological data were obtained, the areas of neuromuscular contacts were photographed and sketched, and the preparations were processed for elecron-microscopic histology. The preparation was fixed with $1 \%$ glutaraldehyde with $0.1 \mathrm{M}$ phosphate buffer ( $\mathrm{pH} \mathrm{7.2)}$ for $2 \mathrm{hr}$ at room temperature. It was then washed with $0.1 \mathrm{M}$ phosphate buffer and postfixed with $1 \% \mathrm{OsO}_{4}$ in $0.1 \mathrm{M}$ phosphate buffer ( $\mathrm{pH} 7.2$ ) for $1 \mathrm{hr}$. The preparation was rinsed with $0.1 \mathrm{M}$ phosphate buffer and $0.1 \mathrm{M}$ acetate buffer (pH 5.2) and was block-stained overnight

Table 1. Specimens used

\begin{tabular}{|c|c|c|c|c|c|c|c|c|c|c|}
\hline & Ref. no. & $\begin{array}{l}\text { Coculture } \\
\text { time }\end{array}$ & $\begin{array}{l}\text { m.e.p.p. } \\
\text { size } \\
(\mathrm{mV})\end{array}$ & $\begin{array}{l}\text { e.p.p. } \\
\text { size } \\
(\mathrm{mV})\end{array}$ & $\begin{array}{l}\text { m.e.p.p. } \\
\text { duration } \\
\text { (msec) }\end{array}$ & $\begin{array}{l}\text { e.p.p. } \\
\text { duration } \\
\text { (msec) }\end{array}$ & $\begin{array}{l}\text { No. of } \\
\text { sections } \\
\text { observed }\end{array}$ & $\begin{array}{l}\text { No. of } \\
\text { sections } \\
\text { lost }\end{array}$ & $\begin{array}{l}\text { Grids } \\
\text { type }\end{array}$ & $\begin{array}{l}\text { Active } \\
\text { zones }\end{array}$ \\
\hline \multirow[t]{3}{*}{ Short-term } & 10 & $4 \mathrm{hr}$ & 1.0 & 1.8 & 9.3 & 9.8 & 434 & 0 & $\mathbf{H}$ & None \\
\hline & 9 & $9.5 \mathrm{hr}$ & $a$ & 11.6 & $a$ & 17 & 90 & 0 & $\mathbf{H}$ & None \\
\hline & 8 & $11 \mathrm{hr}$ & 2.0 & 12.4 & 12 & 11 & 449 & 18 & $\mathbf{S}$ & None \\
\hline Intermediate & 34 & $20 \mathrm{hr}$ & 1.1 & 22.0 & 2.9 & 2.9 & 181 & 6 & $\mathbf{S}$ & Yes \\
\hline \multirow[t]{3}{*}{ Long-term } & 31 & $3 \mathrm{~d}$ & 2.8 & 14.1 & 10 & 9.7 & 147 & 0 & $\mathrm{~S}$ & Yes \\
\hline & 32 & $3 d$ & 1.9 & 17.4 & 31 & 37 & 248 & 3 & $\mathbf{S}$ & Yes \\
\hline & 33 & $3 \mathrm{~d}$ & 1.1 & 7.2 & 9.5 & 4.8 & 278 & 5 & $\mathbf{S}$ & Yes \\
\hline
\end{tabular}

Electrophysiological data are mean values. Duration was measured at half-amplitude. $\mathrm{H}$, hexagonal-mesh grids with about $80 \%$ open area; $\mathrm{S}$, single hole-slot grids.

We observed m.e.p.p.s on oscilloscope but failed to photograph them.

${ }^{b}$ Incipient stage. 

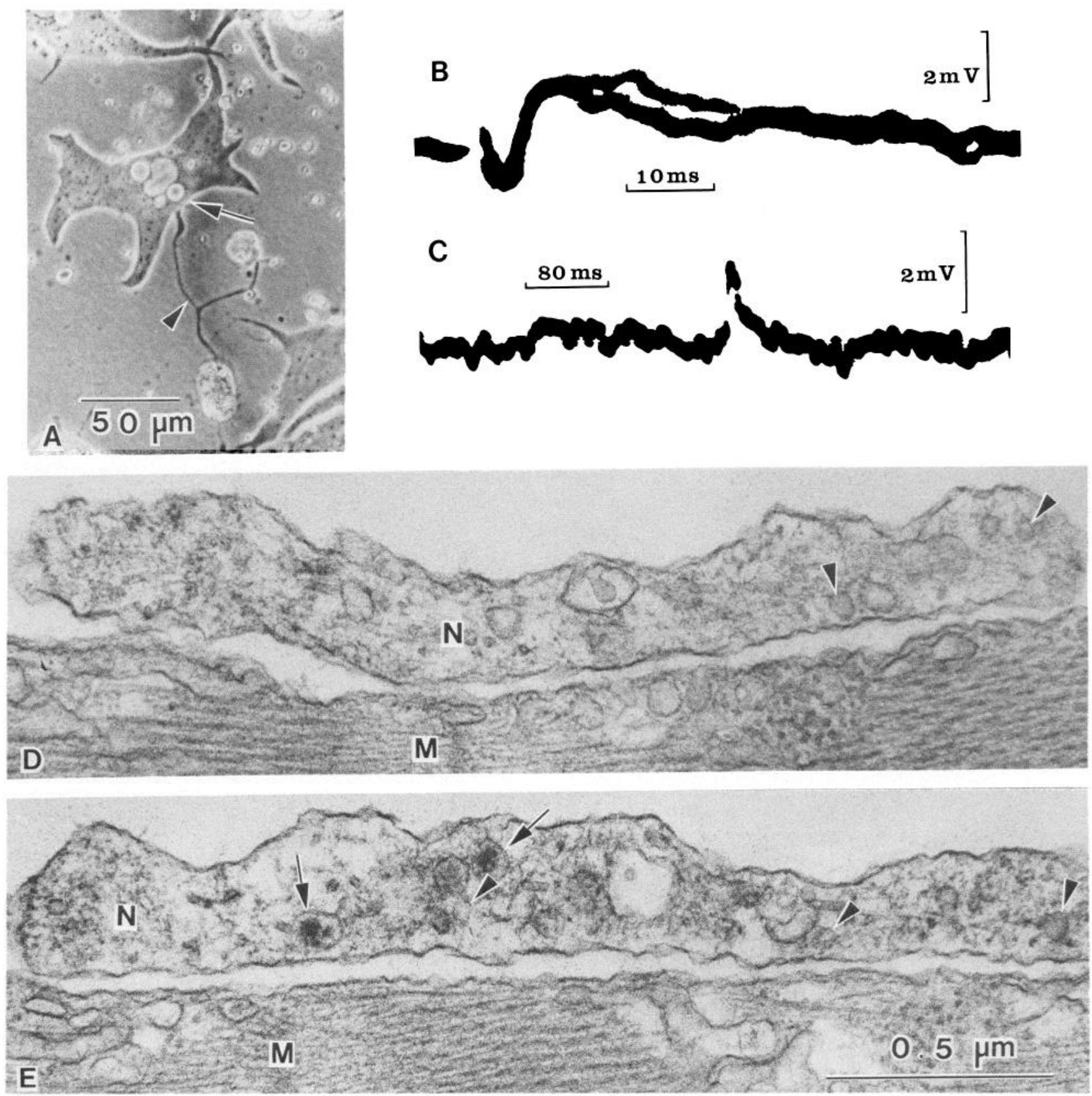

Figure 2. Data from a short-term coculture. Coculture time was $4 \mathrm{hr}$ (ref. no. 10). A, Phase-contrast micrograph immediately after the physiological experiment. Arrow indicates the junctional region, and arrowhead indicates the stimulus site. $B$ and $C$, Records of e.p.p. and m.e.p.p. Resting potential was $-79 \mathrm{mV} . D$ and $E$, Neuromuscular contacts between a nerve growth cone $(N)$ and a muscle cell $(M)$. In the growth cone there are synaptic vesicles (arrowheads), large dense-core vesicles (arrows), and microtubules but no active zone. Synaptic clefts contain no basal lamina, and there is no postsynaptic density.

with $1 \%$ uranyl acetate in $50 \mathrm{~mm}$ acetate buffer $(\mathrm{pH} 5.2)$ at $4^{\circ} \mathrm{C}$.

After dehydration and embedding, the culture dish was removed from the block, and the previously identified neuromuscular contact was again identified under the microscope. The region of the block that contained the neuromuscular contact was serially sectioned in the direction perpendicular to the culture dish bottom. The sections were mounted on grids, double-stained with uranyl acetate and lead citrate, and examined with a Philips 300 EM. We did not attempt to make 3-dimensional reconstructions of the serial sections. In this way, 10 neuromuscular contacts were successfully cut serially and observed (Table 1). In 7 cases the sections were mounted on single hole-slot grids, which enabled us to examine the total area of the sections with the EM. In the other 3 cases (Table 1), sections were mounted on hexagonal grids having about $80 \%$ open area (HEX 460 TB grids, Polaron Instruments, Inc., PA).
Table 1 also contains information about the number of sections observed and the number of sections inadvertently lost during preparation.

\section{Results}

\section{Endplate potentials}

Several hours after adding dissociated neurons to the muscle culture, some muscle cells start to produce spontaneous m.e.p.p.s and nerve-evoked e.p.p.s. Figure $1 A$ illustrates examples of e.p.p.s ( $A 1$ and $A 3$, arrowheads indicate the stimulus) and m.e.p.p.s ( $A 2$, and the right-hand side of $A 3$ ) recorded from a muscle cell cocultured with dissociated neurons for $6 \mathrm{hr}$. Figure 1, $B 1$, shows 
another example of nerve-evoked potentials recorded from a muscle cell cocultured with neurons for $6 \mathrm{hr}$. When the external fluid (normal Ringer's) was switched to a solution in which calcium $(10 \mathrm{~mm})$ was replaced by manganese $(10 \mathrm{~mm})$, the nerveevoked e.p.p. became small $(B 2)$ and then almost disappeared (B3). This effect was reversible (B4). In all, 4 experiments of this kind were performed on early cocultured cells (5-7 hr), and they consistently indicated the inhibitory effect of manganese on the nerve-evoked potentials. Therefore, these nerve-evoked potentials, such as those in Figure 1, would probably be chemical synaptic potentials (endplate potentials).

\section{Short-term coculture}

We have accumulated 4 specimens at early stages of coculture, in which electrophysiology confirmed the presence of both m.e.p.p.s and e.p.p.s, and then serial section electron microscopy was conducted on the same specimens (Table 1). The coculture time ranged from 4 to $11 \mathrm{hr}$.

Figure 2 shows the data obtained from a 4-hr cocultured cell (ref. no. 10 in Table 1). The muscle cell is contacted by a nerve process only at 1 place (Fig. $2 A$, arrow). Electrical stimuli were applied to the nerve process at the location of the arrowhead. Intracellular recording from the muscle cell revealed that stimulation of the neural process evoked e.p.p.s of about $2 \mathrm{mV}$ (Fig. $2 B$ ). Spontaneous m.e.p.p.s were also recorded (Fig. $2 C$ ). Figure $2, D$ and $E$, shows electron micrographs taken from the junctional area indicated in Figure $2 A$. Serial sections of this material revealed that at the neuromuscular contact the neurite enlarged and flattened, showing a profile of an irregularly shaped growth cone roughly $6 \mu \mathrm{m}$ in diameter. Several filopodia, $0.2-0.3 \mu \mathrm{m}$ in diameter, originated from this growth cone. As shown in Figure 2, $D$ and $E$, the cytoplasm of the growth cone contained microtubules, smooth-surfaced endoplasmic reticulum, densecore vesicles about $100 \mathrm{~nm}$ in diameter (arrows in Fig. 2E). Also present were smooth-surfaced clear vesicles (arrowheads in Fig. 2, $D$ and $E$ ) about $50 \mathrm{~nm}$ in diameter; these vesicles are similar in appearance to synaptic vesicles in adult neuromuscular junctions.

Nowhere in the nerve terminal (the growth cone) did we find presynaptic densities. Nor did we find structures where vesicles were clustered in association with presynaptic dense material. Thus, no active zones were found. This is significant, since it has been postulated that the active zones are the sites where the release of transmitter substance occurs (Couteaux and PécotDechavassine, 1970; Dreyer et al., 1973; Heuser et al., 1974). In adult neuromuscular junctions, the postsynaptic membrane facing the nerve terminal shows densities and thickenings; these are considered to represent the region of $\mathrm{ACh}$ receptor aggregates (Cartaud et al., 1973; Fertuck and Salpeter, 1974; Rosenbluth, 1974). We could not find such postsynaptic membrane thickenings or densities in this preparation. The widths of the synaptic cleft were variable; narrow regions $(10-30 \mathrm{~nm})$ predominated with intermingled areas of wider gaps (up to $150 \mathrm{~nm}$ ). There was no basal lamina inside the cleft. These structural features of the contact area are quite different from those of more mature junctions, which are characterized by a wide cleft of about $60 \mathrm{~nm}$, having a continuous basal lamina inside the cleft (see below).

An electron micrograph of a neuromuscular junction taken from another preparation (cocultured for $11 \mathrm{hr}$; cell ref. no. 8, Table 1 ) is shown in Figure $3 A$. In this case the contact area
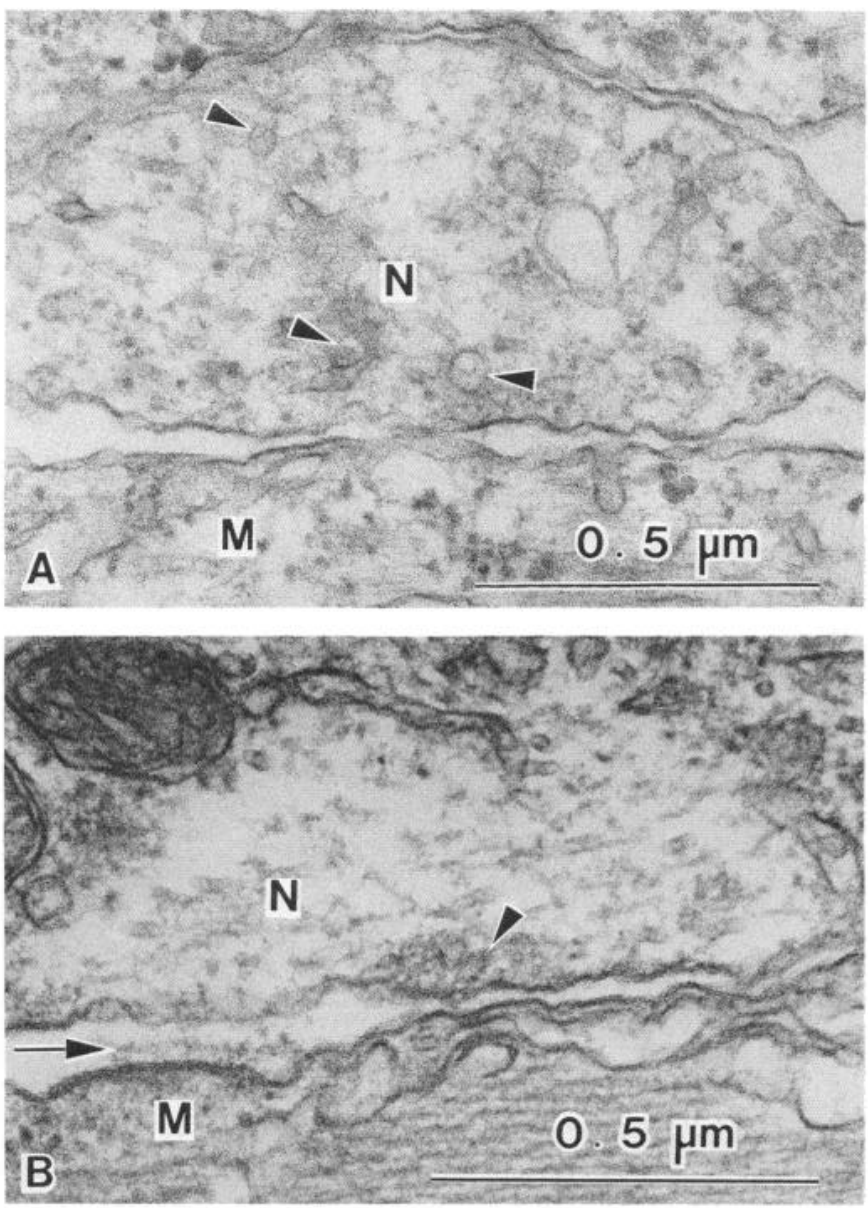

Figure 3. Short-term cocultures. A, Electron micrograph showing a neuromuscular contact obtained from an $11 \mathrm{hr}$ coculture (ref. no. 8). The presynaptic nerve terminal $(N)$ contains synaptic vesicles (arrowheads) but no active zone. There is no postsynaptic density. The synaptic cleft is narrow and lacks basal lamina. $B$, Electron micrograph showing a neuromuscular contact obtained from $6 \mathrm{hr}$ coculture (ref. no. 11). An incipient active zone consisting of vesicle accumulation and a slightly dense material (arrowhead) is seen. At the incipient active zone, the synaptic cleft is still narrow and without basal lamina. Arrow indicates the basal lamina seen at a nonactive zone site. $N$, Nerve terminal; $M$, muscle cell.

was about $20 \mu \mathrm{m}$ in length and the nerve terminal was enlarged (diameter, 1.0-1.5 $\mu \mathrm{m}$ ), forming a varicose structure (Frank and Fischbach, 1979) at 3 places. Figure $3 A$ illustrates 1 of these varicose regions. Structural details of the contact region were similar to those seen in Figure 2, $D$ and $E$. Again, we could not find any active zones in this preparation. The synaptic cleft was generally narrow and lacked the basal lamina. There were several small spots of symmetrical pre- and postsynaptic membrane thickening (puncta adhaerentia) and a few small spots of postsynaptic thickening.

The fine structure of the junction in another preparation (9.5 hr coculture, ref. no. 9) revealed characteristic features similar to those described above, namely, the presence of vesicles and narrow junctional clefts and the absence of active zones and basal lamina. In the last preparation ( $6 \mathrm{hr}$ coculture, ref. no. 11), we encountered 1 spot that appeared to be an incipient stage of an active zone with a few vesicles accumulated with slightly dense material (arrowhead, Fig. 3B). Also only in this material did we find several spots of widened synaptic cleft where the 

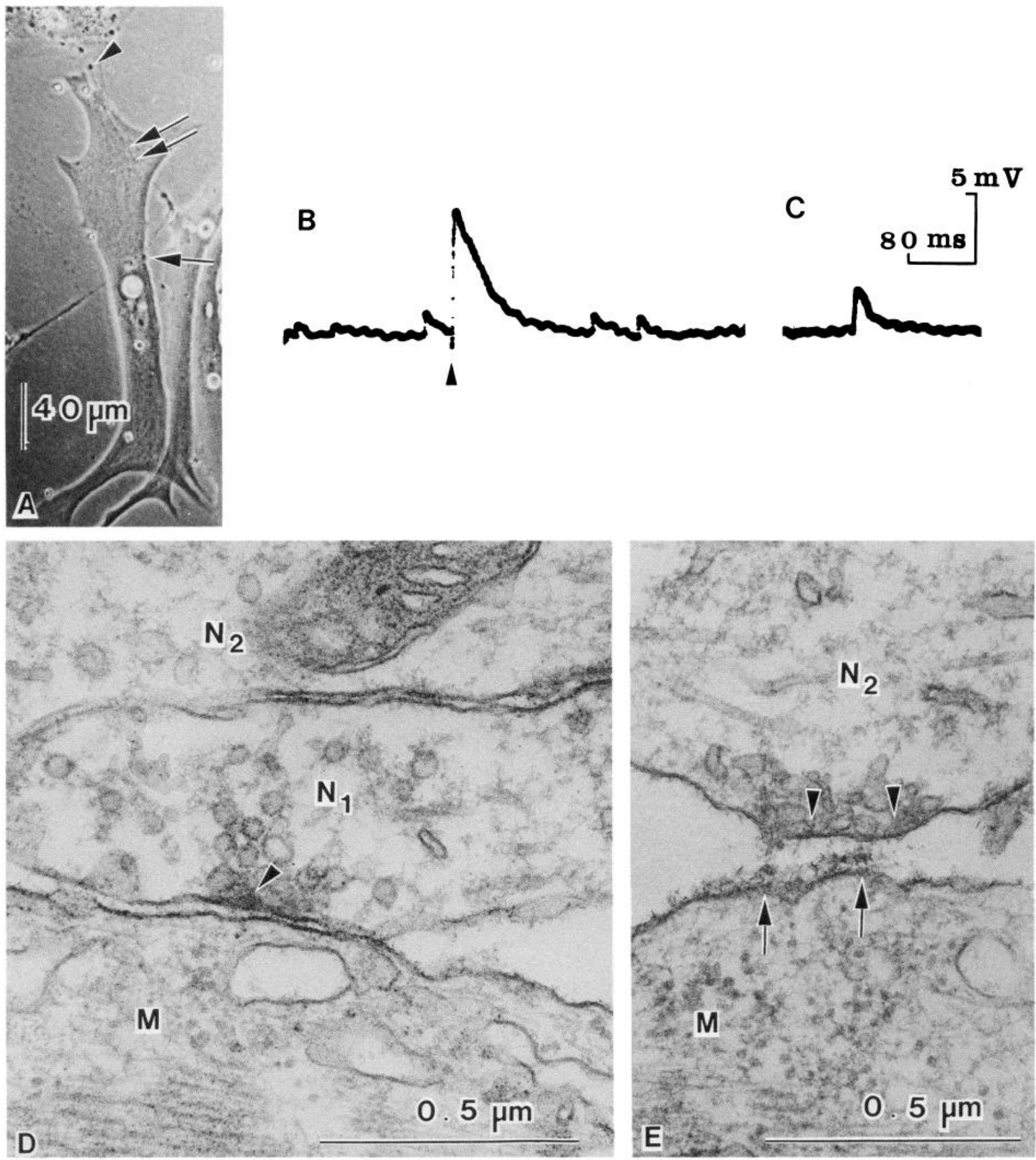

Figure 4. Data from a long-term coculture. Coculture time was $3 \mathrm{~d}$ (ref. no. 32). A, Phase-contrast picture. Arrow and double arrows indicate 2 junctional regions on this muscle cell; Arrowhead indicates the site of stimulation. $B$ and $C$, E.p.p.s and m.e.p.p.s. Arrowhead indicates the stimulus time. Resting potential was $-58 \mathrm{mV} . D$ and $E$, Electron micrographs showing neuromuscular contacts at the region marked by the arrow in $A$. In $D$, one $\left(N_{1}\right)$ of the two neurites $\left(N_{1}\right.$ and $\left.N_{2}\right)$ makes synaptic contact with the muscle cell $(M)$ displaying a well-developed active zone $($ arrowhead $)$. At the active zone the synaptic cleft is narrow without basal lamina, and there is no postsynaptic density. In $E$, the other neurite $\left(N_{2}\right)$ makes synaptic contact with an active zone (arrowheads). At this contact the synaptic cleft is wide, containing basal lamina, and there are postsynaptic densities (arrows).

basal lamina and postsynaptic densities were developed (arrow, Fig. 3B).

One problem to be considered is whether the recorded e.p.p.s and m.e.p.p.s actually came from the same junction that was identified by light and electron microscopy. In all of the 4 cases, light-microscopic observations, which were made during electrophysiological experiments as well as after embedding the material, showed that each muscle cell was innervated at only one region. Serial sections were made covering this entire area, and electron-microscopic observations revealed that in each case only 1 neurite made contact with the muscle cell. (In 1 specimen a second nerve process appeared to be running close to the muscle cell; serial section electron microscopy revealed that this second process did not make contact with the muscle cell.) Another question to consider is whether electrotonic junctions were present among these cultured muscle cells. In all 4 materials 


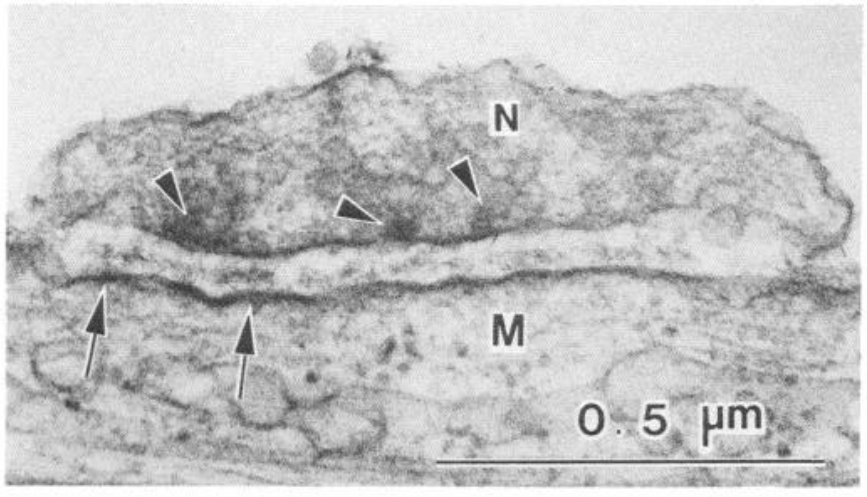

Figure 5. Long-term coculture. Electron micrograph showing a neuromuscular contact from $3 \mathrm{~d}$ coculture (ref. no. 31). The presynaptic nerve terminal $(N)$ contains active zones (arrowheads), and there is postsynaptic density (arrows). The synaptic cleft is wide and contains basal lamina. $M$, Muscle cell.

the stimulated neuron did not extend its processes to the neighboring muscle cells. Thus, the recorded e.p.p.s must have come from the junction studied electron microscopically. In 1 case, neighboring muscle cells did not have any nerve contacts; thus, both the e.p.p.s and m.e.p.p.s must have arisen from the neuromuscular junction that was studied morphologically. In the remaining specimens, the neighboring muscle cells might have been contacted by nerve processes that belonged to other neurons. In these cases, although the e.p.p.s came from the morphologically identified junction, the m.e.p.p.s possibly might have included some coming from neighboring muscle cells. Nevertheless, we think this possibility is remote because, as shown in Table 1, the durations of the e.p.p.s and m.e.p.p.s recorded from each muscle cell were similar, indicating that both probably came from the same junction.

Although we wished to observe the total structural detail of the synaptic region by serial sections, the data are short of perfection. In 3 preparations the serial sections were made without loss of sections (Table 1), but these sections were viewed under the electron microscope by using hexagonal grids with $80 \%$ open area. Hence, about $20 \%$ of the sectional area could not be observed. In the single remaining preparation, we used single-hole slot grids ( $100 \%$ view of the area), and a total of 449 sections were examined; unfortunately, in this preparation 18 sections were lost during the preparation procedure (Table 1 , ref. no. 8).

\section{Intermediate and long-term coculture: overview}

When the coculture time was $1 \mathrm{~d}$ or more, the junctional structure had a more mature appearance and resembled that of the adult neuromuscular junction; i.e., typical active zone structures were present and the cleft contained basal lamina. On the other hand, the light-microscopic pattern of innervation became more complicated, with the presence of double or multiple innervation and occurrence of innervation of neighboring muscle cells being more frequent. Thus, although we attempted to penetrate muscle cells with as simple as possible innervation patterns, strict correlation of structure and function was difficult. In these stages of cocultured materials, however, the rigid correlation became less important for our conclusions.

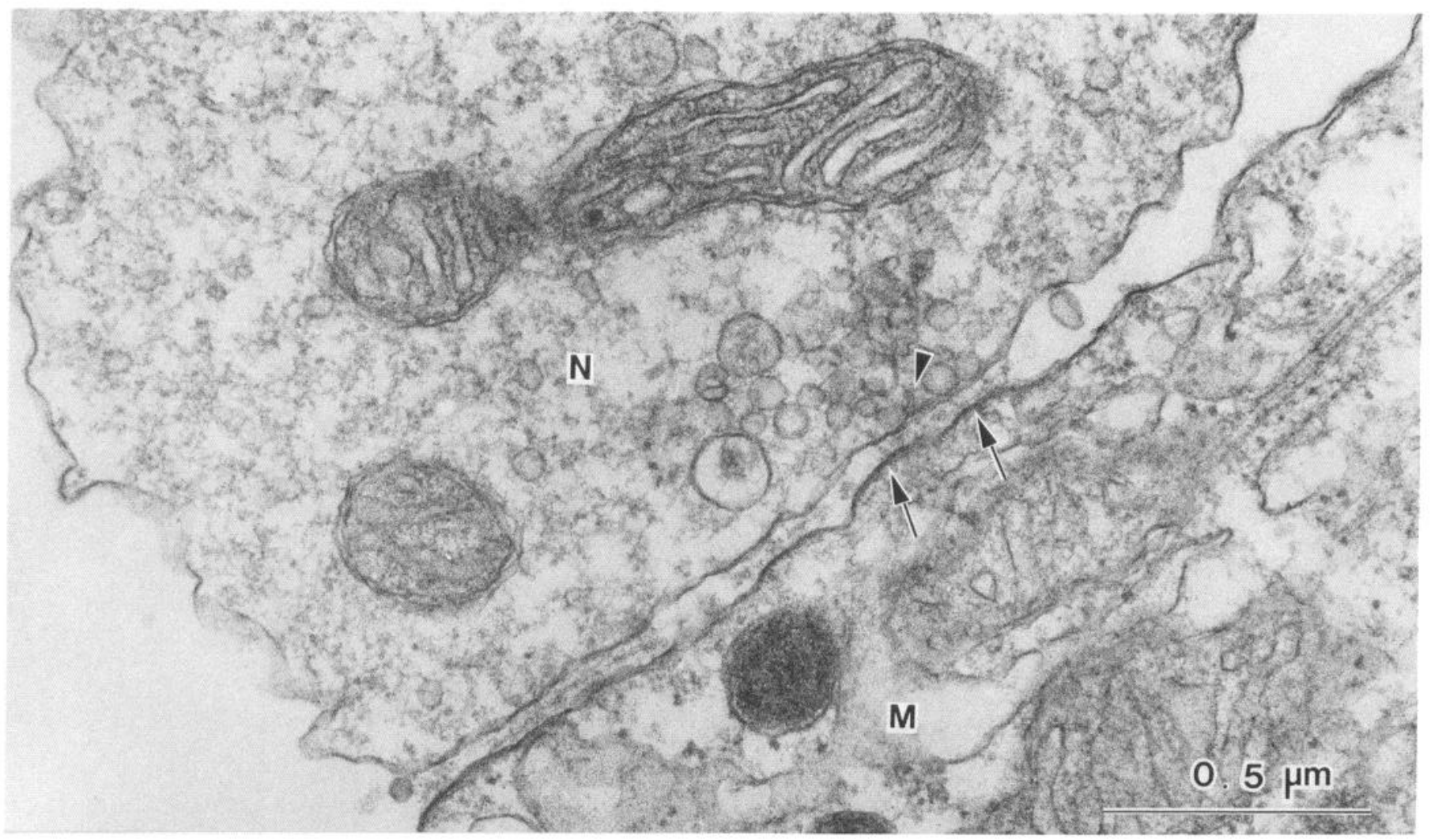

Figure 6. Intermediate coculture. Electron micrograph showing a varicosity of a neurite $(N)$ making synaptic contact with a muscle cell $(M)$ obtained from $29 \mathrm{hr}$ coculture (ref. no. 20). Arrowhead indicates an active zone consisting of vesicle accumulation near the presynaptic density. The synaptic cleft is wide and contains basal lamina. Arrows indicate the postsynaptic density. 
A
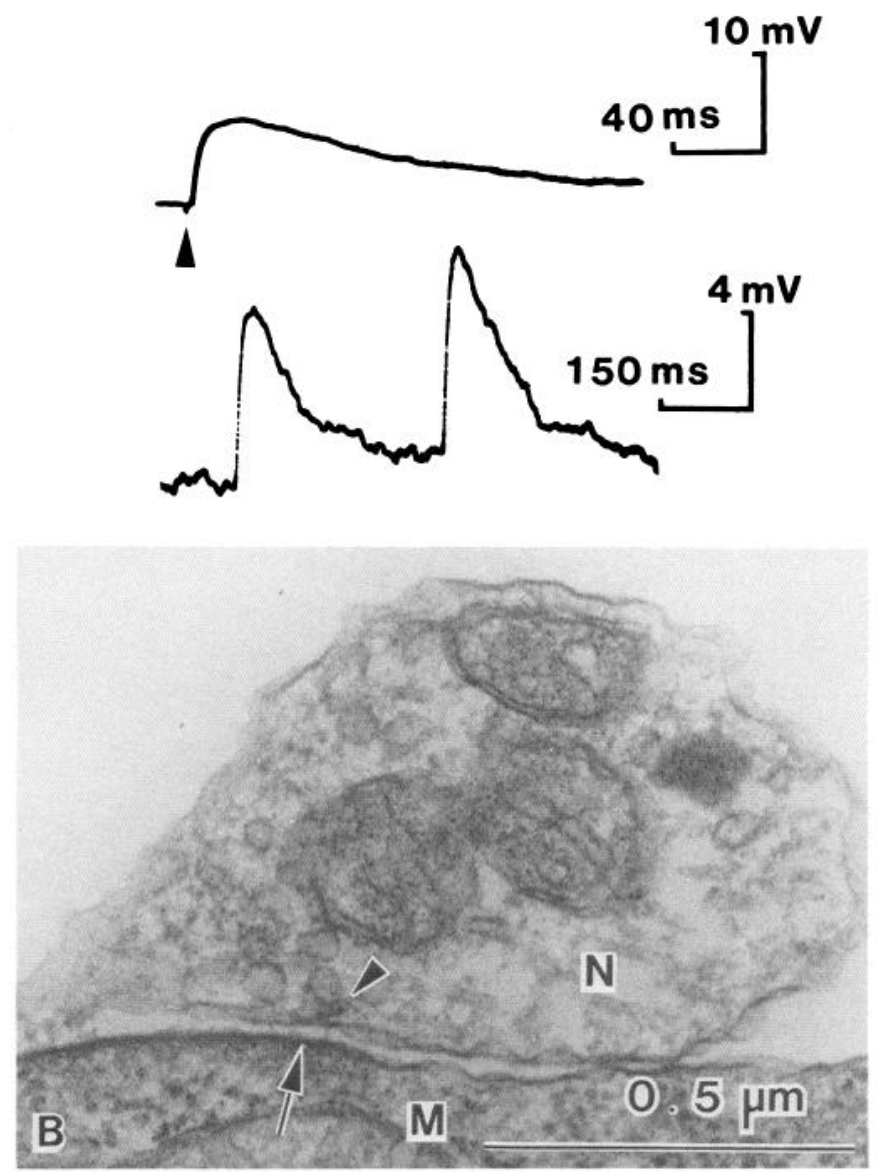

Figure 7. An intermediate coculture with a very slow endplate potential. The coculture time was $23 \mathrm{hr}$ (ref. no. 12). A, Records of an e.p.p. (upper record) and an m.e.p.p. (lower record). Arrowhead indicates the timing of stimulus. Resting potential was $-83 \mathrm{mV}$. B, Electron micrograph showing a neuromuscular contact with an immature active zone (arrowhead). At this active zone, the synaptic cleft is narrow and contains a small amount of amorphous substance, but there is no basal lamina. The postsynaptic density is seen at the site of the active zone (arrow). $N$, Nerve terminal; $M$, muscle cell.

\section{Long-term coculture}

As indicated in Table 1, 3 specimens were observed by serial sections after e.p.p.s and m.e.p.p.s were recorded. The time course of m.e.p.p.s in 1 specimen (ref. no. 33) was definitely slower than that of e.p.p.s, suggesting that the m.e.p.p.s might have originated from a neighboring cell that probably had electronic contact with the impaled cell.

The data from 1 example (ref. no. 32), which was cocultured for $3 \mathrm{~d}$, are shown in Figure 4. Under the light microscope, this muscle cell appeared to be contacted by a single nerve process (Fig. 4A). On examining this specimen under the electron microscope, however, we found that what appeared to be a single nerve process actually consisted of 2 neurites in close proximity. In some places, 1 of these 2 neurites made synaptic contact with the muscle cell, whereas in other places the other neurite made contact. These 2 neurites, running together, made contact with the same muscle cell at 2 different regions (Fig. $4 A$, arrow and double arrows). Under the electron microscope, 1 of these 2 regions (Fig. $4 A$, arrow) displayed more mature structures, in which typical active zones were present. Over the other area of neuromuscular contact (Fig. 4A, double arrows), the axons made only a close apposition without specialization, showing an immature stage of synaptic development.

Figure $4 D$ shows a section over 1 of the synaptic regions (Fig. $4 A$, arrow). We can see the 2 neurites $\left(\mathrm{N}_{1}\right.$ and $\left.\mathrm{N}_{2}\right), 1$ of which $\left(\mathrm{N}_{1}\right)$ makes synaptic contact with the muscle cell, and there is a typical active zone with an accumulation of vesicles (about $50 \mathrm{~nm}$ in diameter) near the site of presynaptic density. This axon contained many synaptic vesicles, and we found a total of 5 active zones belonging to this neurite in this contact region. One characteristic of this particular neurite is that the synaptic clefts were always narrow, about $10-20 \mathrm{~nm}$, and there was no basal lamina in the synaptic cleft (Fig. 4D). The postsynaptic membrane had a slight membrane thickening but did not have a distinct postsynaptic density. In another location over this contact area (Fig. $4 E$ ), the other neurite $\left(\mathrm{N}_{2}\right)$ enlarged to form a varicosity ( $2 \mu \mathrm{m}$ in size), and this varicose region contained an active zone. Here, the synaptic cleft was wide (50-110 nm), and it contained basal lamina; also, the postsynaptic density was present.

In the other 2 cases of $3 \mathrm{~d}$ cocultured specimens, each muscle cell was innervated by 1 axon, and well-developed active zones were found at the neuromuscular contacts. Figure 5 shows an example, in which a presynaptic terminal contained vesicles that clustered on the presynaptic densities forming active zones (arrowheads). The synaptic cleft was wide with the basal lamina inside it.

\section{Intermediate coculture}

Three specimens of neuromuscular junctions cocultured for 20 $29 \mathrm{hr}$ were studied (Table 1). Our data on serial sections confirmed the results by Peng et al. (1979) and showed that the junctions at this stage already contained structures of well-developed synapses with active zones in all three cases. Figure 6 shows an electron micrograph obtained from a $29 \mathrm{hr}$ coculture (ref. no. 20). In this preparation the muscle cell was innervated by 2 neurites (running together); active zones were present only in 1 of these 2 neurites. Figure 6 is a large varicose region (about $3 \mu \mathrm{m}$ in diameter) constituting the synaptic junction. The varicosity contained mitochondria, neurofilaments, dense-cored large vesicles (100-150 $\mathrm{nm}$ in diameter), and many clear vesicles (about $50 \mathrm{~nm}$ ), which accumulated on the presynaptic density, forming an active zone. The synaptic cleft was wide and contained basal lamina. Thus, the general features of $1 \mathrm{~d}$ cocultured junctions were not very different from those of $3 \mathrm{~d}$ cocultured preparations.

In 1 of the $1 \mathrm{~d}$ cocultured specimens, the time courses of both m.e.p.p.s and e.p.p.s were extremely slow (ref. no. 12) with a long decay phase (Fig. 7A). Serial-section electron microscopy revealed that the junctional areas had active zones (Fig. $7 B$ ). The synaptic cleft, however, was narrow $(16-20 \mathrm{~nm})$ and did not contain basal lamina. The postsynaptic density was present. The basal lamina is the site with which a large fraction of synaptic AChE is associated (Hall and Kelly, 1971; Betz and Sakmann, 1973; McMahan et al., 1978). Therefore, the absence of basal lamina at active zone sites could be correlated with the slow decay of m.e.p.p.s and e.p.p.s in this material (see Discussion). 


\section{Discussion}

We recorded m.e.p.p.s and e.p.p.s from neuromuscular synapses at early stages of formation, and the same synapses were studied electron microscopically. These early synapses possess simple structures, characterized by the presence of vesicles, by narrowness of the synaptic cleft, by the absence of obvious basal lamina inside the cleft, and by the lack of typical active zone structures in the presynaptic terminals. The absence of obvious active zones is particularly noteworthy. This appears to indicate that the presence of active zones is not a prerequisite for the occurrence of either m.e.p.p.s or e.p.p.s. For the e.p.p.s to be evoked, the minimal structural requirements, observable with conventional electron-microscopic histology, seem to be the mere presence of synaptic vesicles and close proximity between the pre- and postsynaptic membranes. By correlating electrophysiological properties and serial-section electron-microscopic features, Nakajima et al. (1980) concluded that the presence of presynaptic active zones are not a prerequisite for the occurrence of m.e.p.p.s. Our present conclusion not only agrees with theirs but also extends it by including e.p.p.s. This is important since nerve-evoked e.p.p.s are the principal means by which neurons communicate with muscle cells.

The validity of this conclusion needs to be examined carefully because only about $80 \%$ (in one case, $96 \%$ ) of the total junctional area was observable due to the technical limitation. Moreover, we did observe an incipient active zone in 1 specimen, while we did not observe any active zones in 3 other neuromuscular junctions; all 4 of these specimens produced e.p.p.s as well as m.e.p.p.s.

Suppose that the presence of active zones were a prerequisite of producing e.p.p.s. Then each specimen that produced e.p.p.s should contain an active zone in at least 1 section. If we hypothesize that each 1 of the 4 preparations did contain 1 section with an active zone and that we missed observing the active zone in 3 (out of 4) specimens or worse (i.e., missing all) because of the technical limitation, then the probability of such an occurrence would be only about $1 \%\left[=(0.2)^{2} \times 0.8 \times C_{3,1} \times\right.$ $\left.0.04+(0.2)^{3} \times 0.96+(0.2)^{3} \times 0.04\right]$. Furthermore, if we suppose that there were actually 2 or more sections with active zones in each specimen (this is a more likely situation), then the probability that we failed to observe them in 3 of 4 specimens due to our technical limitation would become far less than $1 \%$. Hence, the hypothesis that the presence of active zones is a prerequisite for e.p.p.s seems to be extremely improbable.

We have observed that in 1 specimen from short-term coculture (ref. no. 10), the presynaptic terminal looked like a growth cone, yet it already produced e.p.p.s and m.e.p.p.s of almost normal time courses. The coculture time of this synapse was 4 $\mathrm{hr}$. Since the $4 \mathrm{hr}$ included the time for neurons to attach to the bottom of the culture dish (a few hours) and the time for the neuron to extend a neurite toward the muscle cell, the actual time of nerve-muscle contact would have been substantially less than $4 \mathrm{hr}$. In fact, previous studies have shown that e.p.p.s could be elicited within 30 min of nerve-muscle contact (Cohen, 1980 ) or as soon as the main part of the growth cone contacted a muscle cell (Kidokoro and Yeh, 1982). Recently, Hume et al. (1983) studied the nerve-evoked release of ACh from growth cones (before making synapses). The time course of this release was very slow, usually with a latency of more than $200 \mathrm{msec}$. These facts indicate that when a growth cone comes in contact with a muscle cell, it undergoes rapid functional changes, so that it can release $\mathrm{ACh}$ at a much faster rate upon nerve stimulation. However, with the conventional thin-section electronmicroscopic histology, we could not find structural changes that might explain these functional changes of the terminal.

The basal lamina inside the synaptic cleft is believed to be the place where a large fraction of synaptic AChE is located (Hall and Kelly, 1971; Betz and Sakmann, 1973; McMahan et al., 1978). Hence, it is puzzling to observe that early synapses, in which the synaptic cleft was narrow and the basal lamina was lacking, produced m.e.p.p.s and e.p.p.s with apparently normal time courses. One way to explain this puzzle is to assume that the ACh content inside each vesicle is small at early stages, as suggested by Kidokoro (1984), and either a small amount of AChE or diffusion through the cleft would be enough for the dissipation of ACh. (See Kullberg et al., 1980, and MoodyCorbett and Cohen, 1981, for the presence of AChE in Xenopus muscle cells in vivo and in vitro.) When the synapse matures, the content of $\mathrm{ACh}$ inside the vesicle may increase (despite the fact that the size of vesicles seems to be constant at $50 \mathrm{~nm}$ ). A larger amount of $\mathrm{ACh}$ released would start to saturate the $\mathrm{ACh}$ receptors, and the time course of e.p.p.s would be prolonged. But at the same time, the cleft is widened, and AChE in the basal lamina starts to develop, and these would facilitate shortening the e.p.p.s. One specimen at the intermediate stage (ref. no. 12) produced e.p.p.s with an extremely slow time course, and in this synapse the synaptic cleft was narrow and there was no basal lamina in the cleft. In this case, the content of ACh in the vesicles was possibly already quite high, whereas the cleft was still narrow and the development of AChE was delayed, resulting in the prolongation of e.p.p.s. Obviously, the discussion in this paragraph is speculative; however, the idea could be tested by experiments, including the histochemical identification of AChE together with electrophysiological and ultrastructural studies.

In summary, the results of the present investigation on the correlation of structure and function could be explained by the following possible developmental sequence: In the growth cone (before attaching to a muscle cell), the vesicles and the calcium channels are located rather randomly and diffusely. Hence, when the nerve is stimulated, it takes a long time for the intracellular calcium concentration to build up in the vicinity of the vesicles. This would explain the long latency of transmitter release in the growth cone (as was discussed by Hume et al., 1983). As soon as the growth cone attaches to the muscle cell surface, rearrangement of the localization of calcium channels and the vesicles may take place, so that now these are situated near each other. This arrangement would result in a more rapid local buildup of calcium concentration near the vesicles upon stimulation and would lead to a more rapid and synchronous release of transmitter substance. However, this strategical rearrangement does not seem to show up as structural changes under conventional thin-section electron microscopy. As development proceeds, this localization of vesicles and calcium channels becomes more pronounced, finally revealing itself as the active zone structure, where the calcium channels and the vesicles are situated in close proximity (Heuser et al., 1974; Llinás, 1977; Pumplin et al., 1981). At the same time, the synaptic cleft is widened, and a layer of basal lamina, with which synaptic $\mathrm{AChE}$ is associated, appears in the cleft. This will prevent prolongation of the time course of e.p.p.s. It should be noted that our finding 
that the active zone is unnecessary for synaptic transmission does not invalidate the notion that the transmitter is released at the active zone in mature synapses. The active zone can be viewed as a structure that renders synaptic transmission more efficient, rather than as a prerequisite for transmission.

\section{References}

Betz, W. (1976) Functional aud non-functional contacts between ciliary neurones and muscle grown in vitro. J. Physiol. (Lond.) 254: 7586.

Betz, W., and B. Sakmann (1973) Effects of proteolytic enzymes on function and structure of frog neuromuscular junctions. J. Physiol. (Lond.) 230: 673-688.

Bird, M. M., and D. W. James (1974) An ultrastructural and electrophysiological study of the development of neuro-muscular junctions between previously dissociated foetal rat cells in vitro. Cell Tissue Res. 155: 269-282.

Cartaud, E., L. Bendetti, J. B. Cohen, J. C. Meunier, and J. P. Changeux (1973) Presence of a lattice structure in membrane fragments rich in nicotinic receptor protein from the electric organ of Torpedo marmorata. FEBS Lett. 33: 109-113.

Cohen, S. A. (1980) Early nerve-muscle synapses in vitro release transmitter over postsynaptic membrane having low acetylcholine sensitivity. Proc. Natl. Acad. Sci. USA 77: 644-648.

Couteaux, R., and M. Pécot-Dechavassine (1970) Vesicules synaptiques et poches au niveau des (〈zones actives〉) de la jonction neuromusculaire. C. R. Acad. Sci. (Paris) 271: 2346-2349.

Crain, S. (1970) Bioelectric interactions between cultured fetal rodent spinal cord and skeletal muscle after innervation in vitro. J. Exp. Zool. 173: 353-370.

Drcycr, F., K. Peper, K. Akert, C. Sandri, and H. Moor (1973) Ultrastructure of the active zone in the frog neuromuscular junction. Brain Res. 62: 373-380.

Fertuck, H. C., and M. M. Salpeter (1974) Localization of acetylcholine receptor by ${ }^{125} \mathrm{I}$-labeled $\alpha$-bungarotoxin binding at mouse motor endplates. Proc. Natl. Acad. Sci. USA 71: 1376-1378.

Fischbach, G. D. (1970) Synaptic potentials recorded in cell cultures of nerve and muscle. Science 169: 1331-1333.

Frank, E., and G. D. Fischbach (1979) Early events in neuromuscular junction formation in vitro. Induction of acetylcholine receptor clusters in the postsynaptic membrane and morphology of newly formed synapses. J. Cell Biol. 83: 143-158.

Hall, Z. W., and R. B. Kelly (1971) Enzymatic detachment of endplate acetylcholinesterace from muscle. Nature [New Biol.] 232: 62-63.

Heuser, J. E., T. S. Reese, and D. M. D. Landis (1974) Functional changes in frog neuromuscular junctions studied with freeze-fracture. J. Neurocytol. 3: 109-131.

Hirano, H. (1967) Ultrastructural study on the morphogenesis of the neuromuscular junction in the skeletal muscle of the chick. Z. Zellforsch. Mikrosk. Anat. 79: 198-208.

Hume, R. I., L. W. Role, and G. D. Fischbach (1983) Acetylcholine release from growth cones detected with patches of acetylcholine receptor-rich membranes. Nature 305: 632-634.

Jacob, M., and T. L. Lentz (1979) Localization of acetylcholine receptors by means of horseradish peroxidase- $\alpha$-bungarotoxin during formation and development of the neuromuscular junction in the chick embryo. J. Cell Biol. 82: 195-211.

Kano, M., and Y. Shimada (1971) Innervation and acetylcholine sensitivity of skeletal muscle cell differentiated in vitro from chick embryo. J. Cell Physiol. 78: 233-242.

Kelly, A. M. (1966) The development of the motor end plate in the rat. J. Cell Biol. 31: 58A.

Kelly, A. M., and S. I. Zacks (1969) The fine structure of motor endplate morphogenesis. J. Cell Biol. 42: 154-169.
Kidokoro, Y. (1984) Two types of miniature endplate potentials in Xenopus nerve-muscle cultures. Neurosci. Res. 1: 157-170.

Kidokoro, Y., and E. Yeh (1982) Initial synaptic transmission at the growth cone in Xenopus nerve-muscle cultures. Proc. Natl. Acad. Sci. USA 79: 6727-6731.

Koenig, J., and M. Pecot-Dechavassine (1971) Relations entre l'apparation des potentiels miniatures spontanes et l'ultrastructure des plaques motrices en voie de reinnervation et de neoformation chez le rat. Brain Res. 27: 43-57.

Kullberg, R. W., F. S. Mikelberg, and M. W. Cohen (1980) Contribution of cholinesterase to developmental decreases in the time course of synaptic potentials at an amphibian neuromuscular junction. Dev. Biol. 75: 255-267.

Llinás, R. R. (1977) Calcium and transmitter release in squid synapse. In Society for Neuroscience Symposia, Vol. 2, Approaches to the Cell Biology of Neurons, W. M. Cowan and J. A. Ferendelli, eds., pp. 139160 , Society for Neuroscience, Bethesda, MD.

McMahan, U. J., J. R. Sanes, and L. M. Marshall (1978) Cholinesterase is associated with the basal lamina at the neuromuscular junction. Nature 271: 172-174.

Moody-Corbett, F., and M. W. Cohen (1981) Localization of cholinesterase at sites of high acetylcholine receptor density on embryonic amphibian muscle cells cultured without nerve. J. Neurosci. 1: 596605 .

Nakajima, Y., Y. Kidokoro, and F. G. Klier (1980) The development of functional neuromuscular junctions in vitro: An ultrastructural and physiological study. Dev. Biol. 77: 52-72.

Nieuwkoop, P. D., and J. Faber (1967) Normal Table of Xenopus laevis (Daudin), North-Holland, Amsterdam.

Pappas, G. D., E. R. Peterson, E. B. Masurovsky, and S. M. Crain (1971) Electron microscopy of the in vitro development of mammalian motor end plates. Ann. NY Acad. Sci. 183: 33-45.

Peng, H. B., and Y. Nakajima (1978) Membrane particle aggregates in innervated and noninnervated cultures of Xenopus embryonic muscle cells. Proc. Natl. Acad. Sci. USA 75: 500-504.

Peng, H. B., P. C. Bridgman, S. Nakajima, A. Greenberg, and Y. Nakajima (1979) A fast development of presynaptic function and structure of the neuromuscular junction in Xenopus tissue culture. Brain Res. 167: 379-384.

Peng, H. B., Y. Nakajima, and P. C. Bridgman (1980) Development of the postsynaptic membrane in Xenopus neuromuscular cultures observed by freeze-fracture and thin-section electron microscopy. Brain Res. 196: 11-31.

Pumplin, D. W., T. S. Reese, and R. Llinás (1981) Are the presynaptic membrane particles the calcium channels? Proc. Natl. Acad. Sci. USA 78: 7210-7213.

Robbins, N., and T. Yonezawa (1971) Physiological studies during formation and development of rat neuromuscular junctions in tissue culture. J. Gen. Physiol. 58: 467-481.

Rosenbluth, J. (1974) Substructure of amphibian motor end plate. Evidence for a granular component projecting from the outer surface of the receptive membrane. J. Cell Biol. 62: 755-766.

Shimada, Y., and D. A. Fischman (1973) Morphological and physiological evidence for the development of functional neuromuscular junctions in vitro. Dev. Biol. 31: 200-225.

Takahashi, T., Y. Nakajima, K. Hirosawa, S. Nakajima, and K. Onodera (1984) The role of active zones in developing neuromuscular junctions. In Neuronal Growth and Plasticity, M. Kuno, ed., pp. 47-55, Japan Scientific Society Press, Tokyo.

Teräväinen, H. (1968) Developnent of the myoneural junction in the rat. Z. Zellforsch. Mikrosk. Anat. 87: 249-265.

Weldon, P. R., and M. W. Cohen (1979) Development of synaptic ultrastructure at neuromuscular contacts in an amphibian cell culture system. J. Neurocytol. 8: 239-259 